\title{
Influence of the drop-beam on the floor slab panel in the construction of waiting rooms for railway stations
}

\author{
Sviatoslav Volinets ${ }^{1}$, Igor Razov ${ }^{1 *}$, and Vladimir Filisuk ${ }^{1}$ \\ ${ }^{1}$ Industrial University of Tyumen, Volodarskogo str.38, Tyumen, 625001, Russia
}

\begin{abstract}
The aim to improve the efficiency of wooden panel houses led to a significant improvement in the design of vertical enclosure structures. However, the structure of the floor slab panel was left unchanged. The authors of this work guessed that it is possible to reduce the cost of panelwooden individual houses without reducing the strength characteristics by increasing the efficiency of the floor structure. With this purpose, dropbeams were introduced, which proved their effectiveness by trial and error method. To determine the influence of the drop-beam on the floor structure, this article presents the calculation of the structure in the first-order approximation according to Hooke's law, and a positive effect on the panel with a span of up to six meters was revealed. Additional research is needed for the panels spanning more than six meters.
\end{abstract}

\section{Introduction}

A new tendency of resettlement of the urban population in the suburbs has been formed and confirmed over the last 50 years.[1] In addition to the obvious advantages of suburban life, this is also explained by people's wish to build their own houses. As a rule, people look for the most budget-friendly options.

Modern building materials market is full of opportunities to build the most efficient and economical houses: the expensive brick has been replaced with foam concrete, and a frame is used instead of timber for building wooden houses.

The latter, comparing to other building materials, is particularly prominent. Comparing with the brick individual house, the cost of which is $\sim$ P 33000 (\$ 485) per square meter, a frame wooden cottage is almost twice as economical with the cost of $\mathrm{P} 18000$ (\$265) per square meter. It also has a shorter construction time: three months for a brick house against two weeks for a frame. Such house also does not put such a serious pressure on the ground, and therefore does not require an expensive ground work, and is able to confine itself to a budget pile foundation.

A serious advantage is also the fact that there is a fierce competition among the manufacturers of wooden panel houses, which forces them to constantly improve vertical enclosure structures.

\footnotetext{
${ }^{*}$ Corresponding author: razovio@mail.ru
} 
In [1], the influence of a large number of node points inside the panel was considered, and variants with a different geometric arrangement of the wall panel stiffeners were also offered. In [2] the wooden wall panels were calculated by the finite element method, resulting with the proof of the optimal thickness of the vertical enclosing structure panels. The use of new panel options, finite element analysis and the effect of changing the geometric scheme of the floor slab has not been considered.

Follesa, M and Fragiacomo, M. modeled and described the behavior of the constructions built with CLT panels in a seismically hazardous situation, showing that the wooden frame panel buildings and constructions have greater seismic stability than others. [3]

At the moment, considering massive migration of people to the suburban territory, the question of increasing the efficiency of wooden frame houses is brought up again. The need to improve the wooden frame houses, whose walls have been modified many times, let us guess that changing the floor structure will enable the construction of more efficient structures.

\section{Materials and Method}

Wooden frame panel houses were built in the same way as any other wooden structures: from timber and boards. However, many modern manufacturers have replaced these materials for OSB and LVL timber. The reason for this, in addition to the reduced cost, is a large amount of glue in them, which helped to largely eliminate such problems of wood as moisture, shrinkage and swelling, as well as flaws in wood. What's more, these materials also work better with pulling and do not crack when the self-tapping screws are used, which are more effective than nailed connection [4]. The panel of these materials was taken as the basis for work, the purpose of which was to reduce the cost of the floor panel, without reducing the strength characteristics.

The prime cost of a standard floor slab panel with rib stiffeners of IPE beam (Fig. 1) and OSB casing is P1467.4 (\$ 21.57). Geometric dimensions: 2500x650x262mm (Fig.2, Fig.3)

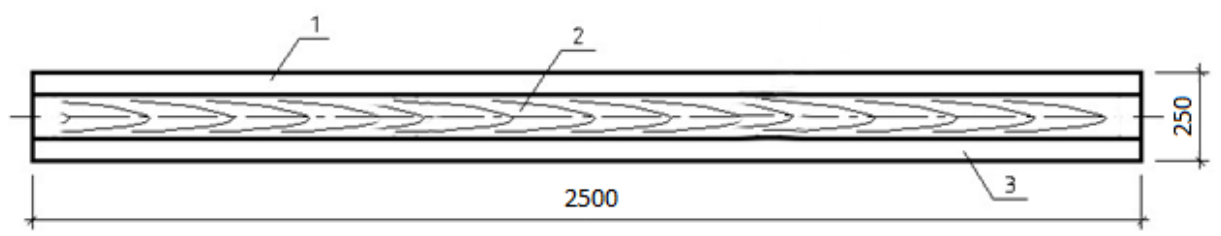

Fig. 1. The longitudinal rib stiffener of the floor panel.

1. The upper flange from the timber LVL $39 x 40 \mathrm{~mm}$.

2. The side from OSB $172 \mathrm{~mm}$.

3. The lower flange from LVL $39 \times 40 \mathrm{~mm}$.

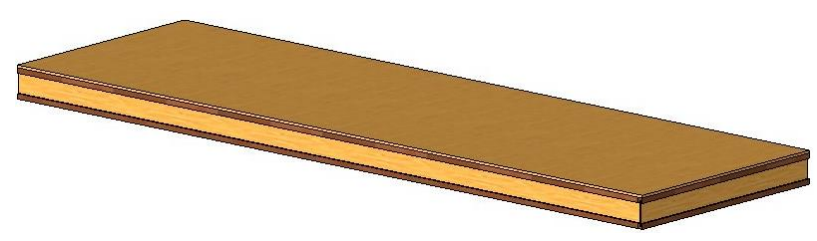

Fig. 2. General view of the panel. 


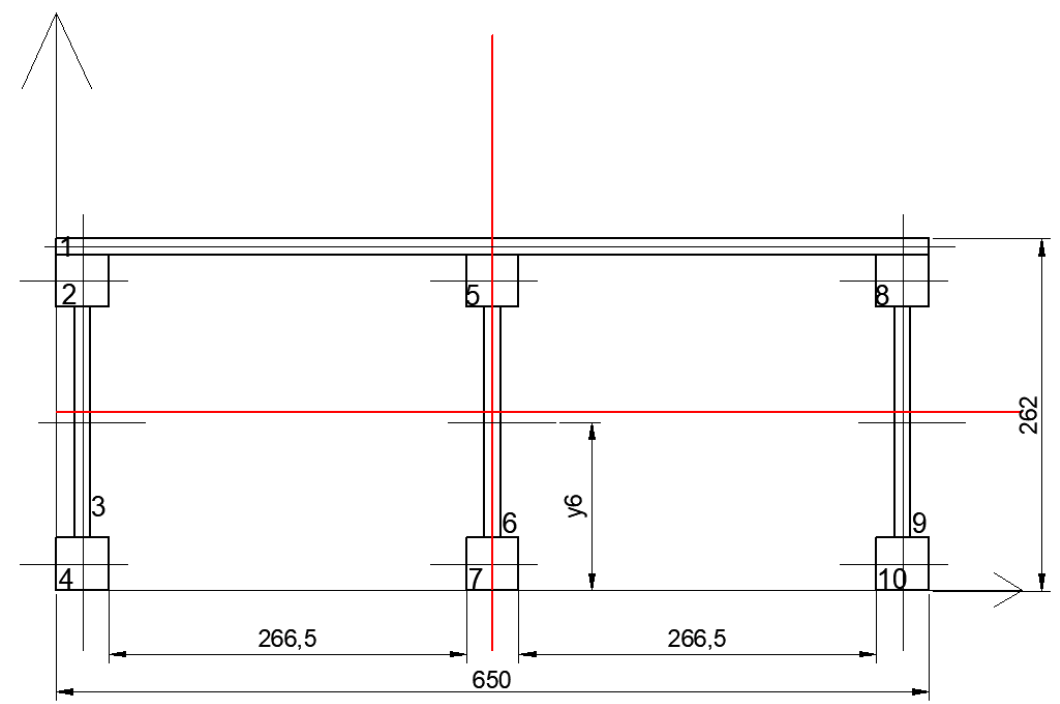

Fig. 3. Cross-section of the floor slab panel.

The authors found out that one way to increase the economic efficiency of the panel is to remove the central stiffener. Since, according to design requirements the maximum allowable distance between the stiffeners should not exceed fifty centimeters, drop beams were introduced, which redistributed the load from the skin to the outer edges.

Studies conducted by Shadravan S. and Ramseyer, C.C., proved the effectiveness of double casing from OSB [5]. However, from the economic point of view, it is much more efficient to use $17 \%$ of the span for the introduction of drop-beam. The tests showed that the modified floor slab panel is 7\% stronger, while it costs $20 \%$ lower (\$17.28) (Fig. 4).

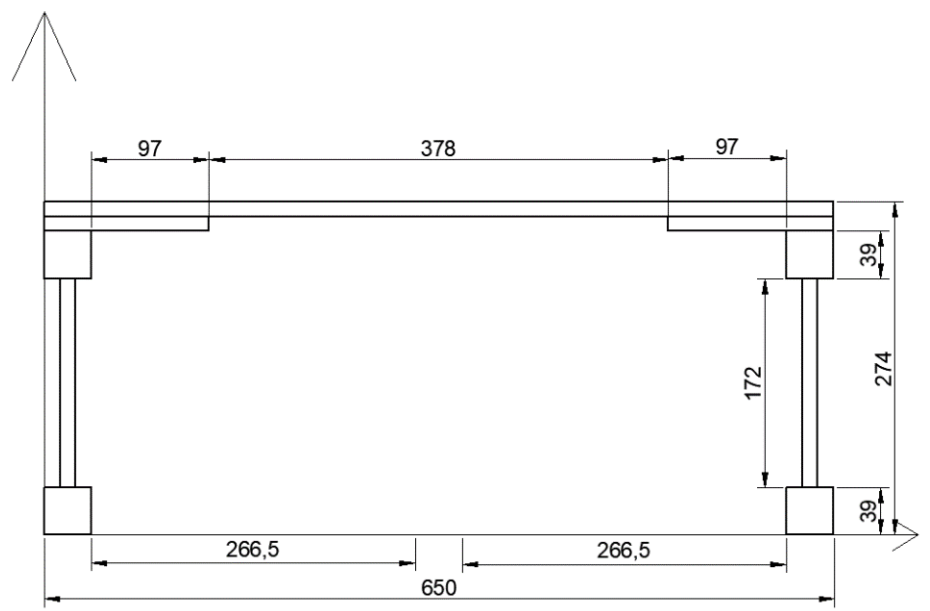

Fig. 4. The cross-section of the modified floor slab panel.

Thus, the possibility of reducing the cost of floor slab panel by introducing a drop-beam was discovered. The third prototype of a panel with geometric dimensions of $2500 \times 650 \times 274$ was created to analyze its effect on the floor panel. Its distinguishing feature was the presence of both a central longitudinal stiffener and a drop-beam (Fig. 5). The cost of the panel was 1654.25 rubles (24.31 \$). For the sake of convenience, the panels were marked: PP1-01, 
PMPP, PPM (Standard panel, panel with two stiffeners, and panel with three stiffeners and drop-beam, respectively).

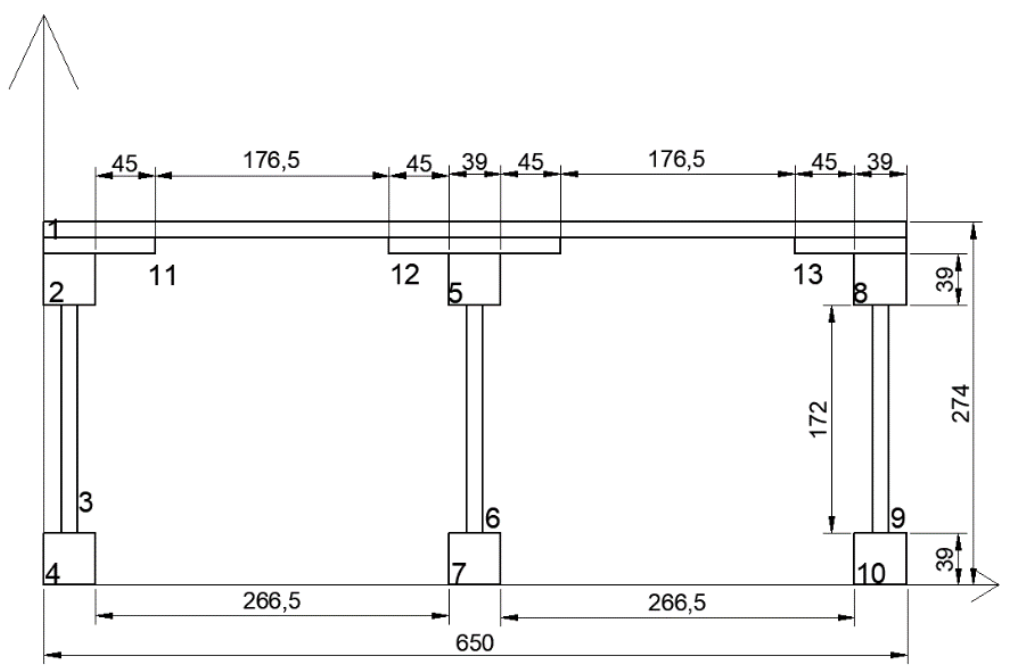

Fig. 5. Cross-section of the panel with three stiffeners and a drop-beam.

This panel was also tested for bending in accordance with industrial standard (GOST) $16504-81$ and collapsed at a load of $3500 \mathrm{~kg}$, which is $40 \%$ of the destruction load for the standard panel. To analyze the effect of the drop-beam on the load-bearing capacity of the floor panel, it is necessary to calculate the panel structure for bending according to the characteristics given. The procedure for determining the load is the following: Calculate the geometric characteristics of the cross-section of the glue panel. Since the beam is made of materials having different elastic moduli (LVL and OSB), it is necessary to calculate the reduced geometric characteristics. As it can be seen from Fig. 5, the moment of inertia of the I cross-section of each part about the neutral axis of the $\mathrm{x}-\mathrm{x}$ section is determined as for the element of rectangular cross-section. It is also necessary to specify the distance from the neutral axis of the cross-section of each of them to the neutral axis of the panel $\mathrm{z}$ and find their areas A. The coefficient of reduction $\eta$ is the ratio of the elastic moduli of the materials from which the beam is made, and, as a rule, the reduction is performed to the most rigid material (lvl) and is equal to 0.29 .

Thus, the final formula for calculating the moment of inertia of the section about the neutral axis of the section of the entire panel $\mathrm{x}-\mathrm{x}$ looks like this:

$$
\begin{aligned}
I_{\text {rd.lvl }}^{x-x}=\eta\left(I_{\text {casing }}^{x-x}\right. & \left.+z_{4} \cdot A_{3}\right)+3 \eta\left(I_{\text {web }}^{x-x}+z_{1} \cdot A_{1}\right)+3\left(I_{\text {flange }}^{x-x}+z_{2} \cdot A_{2}\right) \\
& +3\left(I_{\text {flange }}^{x-x}+z_{3} \cdot A_{2}\right)+2 \eta\left(I_{\text {side drop-beam }}^{x-x}+z_{5} \cdot A_{3}\right) \\
& +\eta\left(I_{\text {side drop-beam }}^{x-x}+z_{6} \cdot A_{4}\right)=16158,83 \mathrm{~cm}^{4}
\end{aligned}
$$

The resistance moment of the panel compound section, reduced to lvl:

$$
W_{\text {rd.lvl }}=\frac{I_{r d . l v l}^{x-x}}{Y_{c}}=\frac{16158.83}{17.7}=912.92 \mathrm{~cm}^{3}
$$

Determine the value of the calculated load on the panel. The calculation scheme of the panel is shown in Figure 6. From the point of view of the design scheme, it is a single-span hinged beam, loaded with two concentrated forces in the thirds of the span. Each of these forces is equal to half of the total load. 

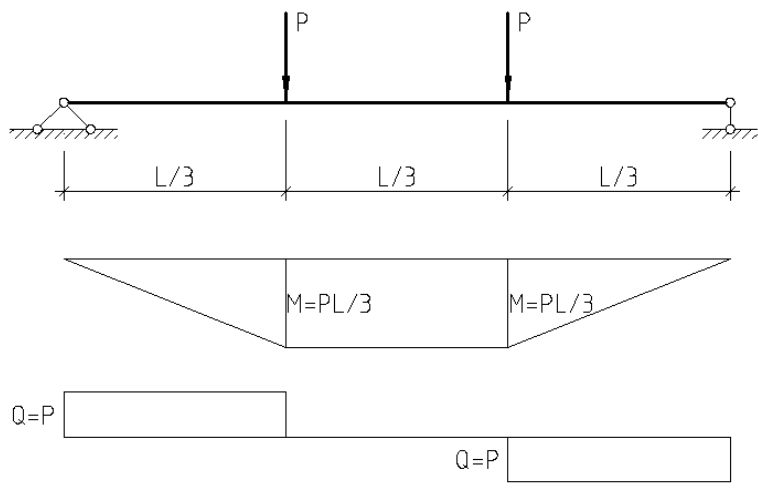

Fig. 6. Calculation scheme of the PPM, bending moment curves and shearing forces diagrams.

The condition for ensuring the bending strength of the cross-section of the beam while subjecting to normal stresses:

$$
\sigma=\frac{M_{\max }}{W W_{\text {rd.lvl }}} \leq R_{c}\left(\frac{\mathrm{kg}}{\mathrm{cm}^{2}}\right)
$$

Thus, the loading is:

$$
P_{c}=\frac{3 W_{r d, l v l} R_{c}}{L}
$$

And it is:

$$
P_{c}=\frac{3 \cdot 912.92 \cdot 200}{190}=2738.76 \mathrm{~kg}
$$

\section{Results}

The calculation of other panels is done in a similar way.

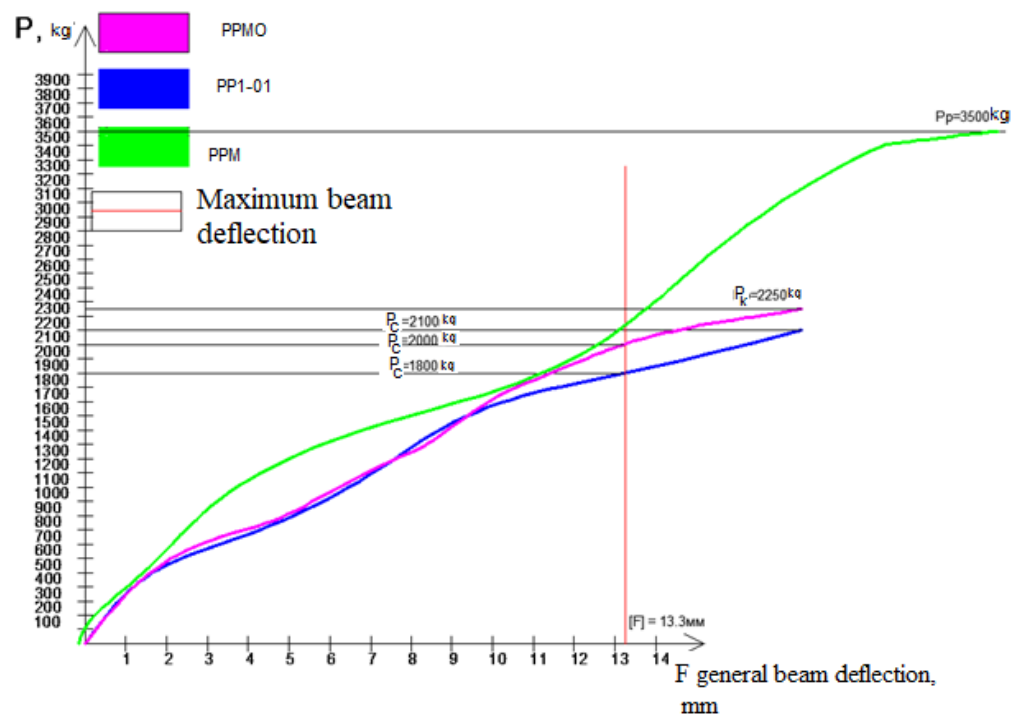

Fig. 7. Comparison of the deflection dependences on the load of the panels graphs. 

2.

The comparison of all three panels for strength characteristics and costs is shown in Table

Table 2. Comparison of all three panels by cost, geometric and strength characteristics.

\begin{tabular}{|c|c|c|c|c|c|}
\hline & $\begin{array}{c}\text { Panel Cross- } \\
\text { sectional } \\
\text { area,cm }\end{array}$ & $\mathrm{W}_{\mathrm{x}}, \mathrm{cm}^{3}$ & $\mathrm{P}_{\text {theor. }}, \mathrm{kg}$ & $\mathrm{P}_{\text {exp. }}, \mathrm{kg}$ & Cost, $\$$ \\
\hline PP1-01 & 231,18 & 12414,1 & 766,3 & 2298,9 & 22,37 \\
\hline PPM & 264,38 & 16152 & 912,92 & 2738,8 & 25,22 \\
\hline PPMO & 203,46 & 11395 & 602,9 & 1808,7 & 17,93 \\
\hline
\end{tabular}

\section{Discussion}

It can be seen from Table 2 and Graph 1 that the PPM that collapsed under a load of $3500 \mathrm{~kg}$ is stronger than the rest of the panels by $40 \%$, with an increase in cost by $20 \%$.

Thus, it becomes obvious that by increasing the span covered by the floor panel, it is also necessary to increase the size of the drop-beam. From this we can make a conclusion that panels with a drop-beam can only be used for small spans of up to 6 meters. In spans larger than 5-6 meters, another reinforcement of the panel construction is necessary.

\section{Conclusions}

This new design is convenient to use in small spans like corridors, sanitary rooms, boiler rooms, and other similar small ones.

The calculation was made in the first approximation. Nailed and glued connections, as well as the cooperation of the casing and drop-beam,were not taken into consideration. However, based on the results of experiments and calculation of the panels for bending, the possibility to use drop-beams for both economizing and strengthening panels was revealed. Based on the results of the tests and calculations described above, it can be concluded that the drop-beam allows either to reduce the cost of the structure by up to $20 \%$, increasing the bending strength by up to $6 \%$, or to increase the structural strength of the panel up to $40 \%$, increasing the prime cost by up to $20 \%$.

The drop-beam has a positive effect on the floor panel, if the span covered by it is not more than 5-6 meters. For larger spans, further research is needed.

\section{References}

1. I. Ladnykh, A. Ibragimov, International Scientific Conference on Advanced in Civil Engineering: Construction - The Formation of Living Environment 365, 062028 (2018)

2. S. Alexandra Morassi, J.L. Ribeiro da Silva, A. Ortenzi, Journal of Building Engineering 15, 78-84 (2018)

3. M. Follesa, M. Fragiacomo, Engineering Structures 168, 628-642 (2018)

4. A.S. Kavelin, Nesushchaya sposobnost' gvozdevykh soyedineniy elementov derevyannykh stenovykh paneley (Rostov-on-Don, 2003)

5. S. Shadravan, C.C. Ramseyer, Structures 16, 82-96 (2018) 